\title{
Interferon Resistance of Emerging SARS-CoV-2 Variants
}

3

${ }^{3}$ Division of Pulmonary Sciences and Critical Medicine, Department of Medicine, 


\section{Abstract}

24 The emergence of SARS-CoV-2 variants with enhanced transmissibility, pathogenesis and

25 resistance to vaccines presents urgent challenges for curbing the COVID-19 pandemic. While

26 Spike mutations that enhance virus infectivity or neutralizing antibody evasion may drive the

27 emergence of these novel variants, studies documenting a critical role for interferon responses in

28 the early control of SARS-CoV-2 infection, combined with the presence of viral genes that limit

29 these responses, suggest that interferons may also influence SARS-CoV-2 evolution. Here, we

30 compared the potency of 17 different human interferons against multiple viral lineages sampled

31 during the course of the global outbreak, including ancestral and four major variants of concern.

32 Our data reveal increased interferon resistance in emerging SARS-CoV-2 variants, suggesting

33 that evasion of innate immunity may be a significant, ongoing driving force for SARS-CoV-2

34 evolution. These findings have implications for the increased lethality of emerging variants and

35 highlight the interferon subtypes that may be most successful in the treatment of early infections.

\section{Author Summary}

38 In less than 2 years since its spillover into humans, SARS-CoV-2 has infected over 220 million

39 people, causing over 4.5 million COVID-19 deaths. High infection rates provided substantial

40 opportunities for the virus to evolve, as variants with enhanced transmissibility, pathogenesis,

41 and resistance to vaccine-elicited neutralizing antibodies have emerged. While much focus has

42 centered on the Spike protein which the virus uses to infect target cells, mutations were also

43 found in other viral proteins that might inhibit innate immune responses. Specifically, viruses

44 encounter a potent innate immune response mediated by the interferons, two of which, IFN $\alpha 2$

45 and IFN $\beta$, are being repurposed for COVID-19 treatment. Here, we compared the potency of 
bioRxiv preprint doi: https://doi.org/10.1101/2021.03.20.436257; this version posted December 10,2021 . The copyright holder for this preprint (which was not certified by peer review) is the author/funder, who has granted bioRxiv a license to display the preprint in perpetuity. It is made available under aCC-BY-NC-ND 4.0 International license.

46 human interferons against ancestral and emerging variants of SARS-CoV-2. Our data revealed

47 increased interferon resistance in emerging SARS-CoV-2 strains that included the alpha, beta,

48 gamma and delta variants of concern, suggesting a significant, but underappreciated role for

49 innate immunity in driving the next phase of the COVID-19 pandemic.

50 


\section{$51 \quad$ Results}

52 The human genome encodes a diverse array of antiviral interferons (IFNs). These include the

53 type I IFNs (IFN-Is) such as the 12 IFN $\alpha$ subtypes, IFN $\beta$ and IFN $\omega$ that signal through

54 ubiquitous IFNAR receptor, and the type III IFNs (IFN-IIIs) such as IFN $\lambda 1$, IFN $\lambda 2$ and IFN $\lambda 3$

55 that signal through the more restricted IFN $\lambda$ R receptor that is present in lung epithelial cells [1].

56 IFN diversity may be driven by an evolutionary arms-race in which viral pathogens and hosts

57 reciprocally evolve countermeasures [2]. For instance, the IFN $\alpha$ subtypes exhibit $>78 \%$ amino

58 acid sequence identity, but IFN $\alpha 14$, IFN $\alpha 8$ and IFN $\alpha 6$ most potently inhibited HIV-1 in vitro

59 and in vivo [3-5], whereas IFN 25 most potently inhibited influenza H3N2 in lung explant

60 cultures [6]. Even though SARS-CoV-2 was sensitive to IFN $\alpha 2$, IFN $\beta$, and IFN $\lambda$ [7-9], and

61 clinical trials of IFN $\alpha 2$ and IFN $\beta$ demonstrated therapeutic promise for COVID-19 [10-12], a

62 direct comparison of multiple IFN-Is and IFN-IIIs against diverse SARS-CoV-2 variants of

63 concern has not yet been done.

64

65 The current study was initially undertaken to determine which IFNs would best inhibit SARS-

66 CoV-2. These first set of experiments were performed between December 2020 and March 2021,

67 and we selected 5 isolates from prominent lineages [13] during this phase of the pandemic (Fig

68 1, S1 Table). USA-WA1/2020 is the standard strain utilized in many in vitro and in vivo studies

69 of SARS-CoV-2 and belongs to lineage A [13]. It was isolated from the first COVID-19 patient

70 in the US, who had a direct epidemiologic link to Wuhan, China, where the virus was first

71 detected [14]. By contrast, subsequent infection waves from Asia to Europe [15] were associated

72 with the emergence of the D614G mutation [16]. Lineage B strains with G614 spread globally

73 and displaced ancestral viruses with striking speed, likely due to increased transmissibility [17, 
74 18]. These strains accumulated additional mutations in Italy as lineage B.1 which then

75 precipitated a severe outbreak in New York City [19]. Later in the United Kingdom (U.K.),

76 lineage B.1.1.7 acquired an N501Y mutation associated with enhanced transmissibility [13].

77 Lineage B.1.351, first reported in South Africa, additionally acquired an additional E484K

78 mutation associated with resistance to neutralizing antibodies [20, 21]. Both B.1.1.7 and B.1.351

79 were reported in multiple countries and in some cases have become dominant for extended

80 periods [22]. We obtained representative SARS-CoV-2 isolates of the B, B.1, B.1.1.7 and

81 B.1.351 lineages (S1 Table). Each stock was sourced from beiresources.org and amplified once

82 in a human alveolar type II epithelial cell line (A549) that we have stably transduced with the

83 receptor ACE2 (A549-ACE2) (S1A Fig).

85 A549-ACE2 cells were pre-incubated with 17 recombinant IFNs (PBL Assay Science) overnight

86 in parallel and in triplicate, then infected with a non-saturating virus dose for $2 \mathrm{~h}$ (S1B Fig). We

87 normalized the IFNs based on molar concentrations similarly to our previous work with HIV-1

88 [3, 23]. To enable high-throughput evaluation of the antiviral activities of the numerous IFNs

89 against the multiple live SARS-CoV-2 isolates, we used a quantitative PCR (qPCR) assay to

90 determine amounts of virus produced 24 hours after infection (Fig 2A). Initial dose-titrations

91 showed that a $2 \mathrm{pM}$ concentration fell within the dynamic range of activity and maximally

92 distinguished the antiviral activities of IFNs with widely divergent potencies, i.e., IFN $\beta$ and

93 IFN $\lambda 1$ (S1C Fig). Of note, the IFN $\beta$ and IFN $\lambda 1$ doses used did not significantly affect cell

94 viability (S1D Fig). Thus, $2 \mathrm{pM}$ doses were used for additional antiviral activity testing. We also

95 evaluated the qPCR assay against a VeroE6 plaque assay using triplicate serial dilutions of a

96 SARS-CoV-2 isolate (B.1.351). Virus titers obtained using these two assays were strongly 
97 correlated (S2A Fig). However, the VeroE6 plaque assay had 2-log lower dynamic range; we

98 estimate that 1 plaque forming unit corresponds to 900 SARS-CoV-2 N1 copies (S2A Fig).

99 Virus copy numbers also correlated with the numbers of primary airway epithelial cells infected

100 with different SARS-CoV-2 variants as quantified by immunofluorescence (S2B Fig). Thus, we

101 employed the qPCR assay to robustly distinguish the antiviral activity of the different

102 interferons.

103

104 In the absence of IFN, all 5 isolates reached titers of $\sim 10^{4}-10^{6}$ copies per $5 \mu$ input of RNA

105 extract (Fig 2). Using absolute copy numbers (Fig 2) or values normalized to mock as $100 \%$ (S2

106 Fig), the 17 IFNs showed a range of antiviral activities against SARS-CoV-2. The 3 IFN $\lambda$

107 subtypes exhibited none to very weak (<2-fold) antiviral activities compared to most IFN-Is (Fig

1082 and S3 Fig, blue bars). This was despite the fact that the assay showed a robust dynamic range,

109 with some IFNs inhibiting USA-WA1/2020 > 2500-fold to below detectable levels (Fig 2A). IFN

110 potencies against the 5 isolates correlated with each other (S4 Fig), and a similar rank-order of

111 IFN antiviral potency was observed for G614+ isolates (Fig 2B, S3 Fig). Overall, IFN $\alpha 8$, IFN $\beta$

112 and IFN $\omega$ were the most potent, followed by IFN $\alpha 5$, IFN $\alpha 17$ and IFN $\alpha 14$ (Fig 2C); the type III

$113(\lambda)$ IFNs were least potent.

115 The molecular basis for the diverse antiviral effects of the highly related IFN $\alpha$ subtypes has been

116 an active area of investigation, particularly with regard to the relative contributions of

117 quantitative (signaling) versus qualitative (differential gene regulation) mechanisms [2-5]. We

118 reported that inhibition of $\mathrm{HIV}-1$ by the IFN $\alpha$ subtypes correlated with IFNAR signaling 119 capacity and binding affinity to the IFNAR2 subunit [3, 23]. IFNAR signaling capacity, as 
measured in an IFN-sensitive reporter cell line (iLite cells; Euro Diagnostics), correlated with the

121 antiviral potencies of the IFN $\alpha$ subtypes against SARS-CoV-2 lineages A and B, but not B.1,

122 B.1.351 or B.1.1.7 (Fig 3A). IFNAR binding affinities as measured by surface plasmon

123 resonance by the Schreiber group [24] did not correlate with IFN $\alpha$ subtype inhibition of SARS-

124 CoV-2 (Fig 3B). As the recombinant IFNs used in this study was from the same source as that of

125 the prior HIV-1 study [3, 23], we also determined if the IFNs that potently inhibit HIV-1 also

126 function similarly against SARS-CoV-2. Notably, the correlations between SARS-CoV-2 and

127 HIV-1 inhibition [3] were weak at best (Fig 3C). These findings suggested that IFN-mediated

128 control of SARS-CoV-2 isolates may be qualitatively distinct from that of HIV-1.

130 We generated a heat-map to visualize the antiviral potency of diverse IFNs against the 5 isolates

131 and observed marked differences in IFN sensitivities (Fig 4A). Pairwise analysis of antiviral

132 potencies between isolates collected early (January 2020) and later (March-December 2020)

133 during the pandemic were performed against the 14 IFN-Is (IFN-III data were not included due

134 to low antiviral activity, Fig. 2). The overall IFN-I sensitivity of USA-WA1/2020 and

135 Germany/BavPat1/2020 isolates were not significantly different from each other (Fig 4B). In

136 contrast, relative to Germany/BavPat1/2020, we observed 17 to 122 -fold IFN-I resistance of the

137 emerging SARS-CoV-2 variants (Fig 4C), with the B.1.1.7 strain exhibiting the highest IFN-I

138 resistance (this can also be seen in Fig. 3). The level of interferon resistance was especially

139 striking when compared to the early pandemic USA-WA1/2020 strain, where emerging SARS-

140 CoV-2 variants exhibited 25 to 322-fold higher IFN-I resistance (Fig 4D). 
142 The experiments to this point allowed for the simultaneous analysis of 17 IFNs against multiple

143 SARS-CoV-2 isolates, but did not provide information on how different IFN-I doses affect virus

144 replication. It also remained unclear if the emerging variants were resistant to IFN-IIIs. We

145 therefore titrated a potent (IFN $\beta ; 0.002$ to $200 \mathrm{pM}$ ) and a weak (IFN $\lambda 1 ; 0.02$ to $2000 \mathrm{pM})$

146 interferon against the lineage A, B, B.1, B.1.1.7 and B.1.351 viruses (Fig 5 and S5 Fig). Of note,

147 as the pandemic progressed in the past year, new variants of concern (VOCs) became dominant

148 in several countries; the WHO implemented a simplified Greek letter nomenclature for these

149 VOCs. We therefore included 3 additional VOCs, which were also obtained from the BEI

150 repository: (1) a second B.1.1.7 (alpha) isolate, England/204820464/2020; (2) an isolate from

151 lineage P.1 (gamma), which branched off from lineage B.1.1.28; and (3) an isolate from lineage

152 B.1.617.2 (delta) (S1 Table). Lineage P.1 was first described in an outbreak of SARS-CoV-2 in

153 Manaus, Brazil, which occurred in a population with high levels of prior infection. P.1

154 independently acquired the E484K mutation [25, 26] (Fig 1A, S1 Table). The delta strain was

155 first reported in India in early 2021 [27, 28], and as of July 2021, has become the dominant

156 variant worldwide, including the USA [29]. The delta strain was particularly concerning as it was

157 frequently observed in breakthrough infections among fully-vaccinated individuals [30, 31].

159 The lineage A and B isolates were similarly inhibited by IFN $\beta$ and IFN $\lambda 1$ (S5A Fig). Comparing

160 B to B.1, the $50 \%$ inhibitory concentration $\left(\mathrm{IC}_{50}\right)$ of the B.1 isolate was 2.6 and 5.5 -fold higher

$161 \mathrm{IC}_{50}$ for IFN $\lambda 1$ and IFN $\beta$, respectively (S5B Fig). Comparing B to B.1.1.7, the B.1.1.7 variants

$162 \mathrm{IC}_{50} \mathrm{~s}$ were 4.3 to 8.3 -fold higher for $\mathrm{IFN} \beta$ and 3.0 to 3.5 higher for IFN 1 (Fig 5A).

163 Interestingly, maximum inhibition was not achieved with either IFN $\beta$ or IFN $\lambda 1$ against the

164 B.1.1.7 variant, plateauing at 15 to 20-fold higher levels than the ancestral lineage B isolate (Fig. 
165 5A), which was in sharp contrast to the lineage B.1 isolate (S5B Fig). In a separate experiment,

166 the B.1.351 variant was also more resistant to IFN $\beta$ (43-fold) and IFN $\lambda 1$ (26-fold) compared to

167 the lineage B isolate (Fig 5B). Here, however, maximum inhibition was achieved with IFN $\beta$. The

168 P.1 variant also exhibited higher resistance to IFN $\beta$ (1.9-fold) and IFN $\lambda 1$ (4.4-fold), and the

169 plateau concentration for antiviral activity was $>10$-fold higher for IFN $\beta$ than for the lineage B

170 isolate (Fig. 5C). Consistent with the findings with the other VOCs, the B.1.617.2 (delta) variant

171 was also more resistant to IFN $\beta$ (6.7-fold) (Fig. 5D). Although similar IC50s were obtained with

172 IFN $\lambda 1$, the B.1.617.2 isolate had higher residual replication at the highest doses than the

173 ancestral lineage B isolate (Fig. 5D).

174

175 Two months after our initial preprint [32], Thorne et al posted data that in Calu-3 cells, a B.1.1.7

176 isolate, was more resistant to IFN $\beta$ than a 'first wave' lineage B isolate [33]. We found that

177 lineage A and B isolates replicated poorly in Calu-3 cells, making these cells unsuitable for IFN

178 resistance comparisons between ancestral versus emerging variants (S6A Fig). This was in sharp

179 contrast to A549-ACE2 cells, where we observed high levels of virus production (>105 copies)

180 of all strains studied (S1B Fig). Notably, comparable titers were obtained between the B.1 and

181 B.1.1.7 isolates in Calu-3 cells (S6A Fig). In these cells, the B.1.1.7 isolate was 50-fold more

182 resistant to IFNג1 than the B.1 isolate (S6B Fig). We also demonstrate that the B.1.1.7 and

183 B.1.617.2 isolates were more resistant to IFN $\beta$ than the B.1 isolate (S6C Fig). Altogether, our

184 data demonstrate that the B.1, B.1.1.7, B.1.351, P.1 and B.1.617.2 isolates have evolved to resist

185 the IFN-I and IFN-III response. 


\section{Discussion}

188 Numerous studies have shown that interferons are important for host defense against SARS-

$189 \mathrm{CoV}-2$. This sarbecovirus is believed to have recently crossed the species barrier to humans,

190 either directly from bats or via an intermediate mammalian host(s) [34]. Here, we demonstrate

191 that SARS-CoV-2 has in fact evolved after host switching to become more resistant to human

192 interferons. Moreover, we establish an order of antiviral potency for the diverse type I and III

193 IFNs. IFN $\lambda$ initially showed promise as an antiviral that can reduce inflammation [35], but our

194 data suggest that for SARS-CoV-2, higher doses of IFN $\lambda$ may be needed to achieve a similar

195 antiviral effect in vivo as the IFN-Is. Nebulized IFN $\beta$ showed potential as a therapeutic against

196 COVID-19 [11], and our data confirm IFN $\beta$ is highly potent against SARS-CoV-2. However,

197 IFN $\beta$ was also linked to pathogenic outcomes in chronic mucosal HIV-1 [23], murine LCMV

198 [36] and if administered late in mice, SARS-CoV-1 and MERS-CoV [37, 38] infection. We

199 previously reported that IFN $\beta$ upregulated 2.4-fold more genes than individual IFN $\alpha$ subtypes,

200 suggesting that IFN $\beta$ may induce more pleiotropic effects [23]. Among the IFN $\alpha$ subtypes,

201 IFN $\alpha 8$ showed similar anti-SARS-CoV-2 potency as IFN $\beta$. IFN $\alpha 8$ also exhibited high antiviral

202 activity against HIV-1 [3], raising its potential for treatment against both pandemic viruses.

203 Notably, IFN $\alpha 8$ appeared to be an outlier in this regard, as the antiviral potencies of the IFN $\alpha$

204 subtypes against SARS-CoV-2 and HIV-1 generally did not strongly correlate (Fig. 3C). IFN $\alpha 6$

205 potently restricted HIV-1 [3, 4] but was one of the weakest IFN $\alpha$ subtypes against SARS-CoV-2.

206 Conversely, IFN $\alpha 5$ strongly inhibited SARS-CoV-2, but weakly inhibited HIV-1 [3]. This lack

207 of correlation is a key point for future studies. Of note, the high potency of IFN $\alpha 5$ and low

208 potency of IFN $\alpha 6$ against an isolate of SARS-CoV-2 (not a variant of concern) were

209 corroborated by another group [39]. Collectively, these data strengthen the theory that diverse 
210 IFNs may have evolved to restrict distinct virus families [2, 23]. The mechanisms underlying

211 these interesting qualitative differences remain unclear. While IFNAR signaling contributes to

212 antiviral potency [3, 4, 24], diverse IFNs may have distinct abilities to mobilize antiviral

213 effectors in specific cell types. Comparing the interferomes induced by distinct IFNs in lung

214 epithelial cells [39] may be useful in prioritizing further studies on this point.

216 Most significantly, our data reveal for the first time the concerning trend for SARS-CoV-2

217 variants emerging later in the pandemic - in the setting of prolific replication of the virus in

218 human populations - to resist the antiviral interferon response. Prior to the present work, the

219 emergence and fixation of variants was linked to enhanced viral infectivity and/or neutralizing

220 antibody evasion due to mutations in the Spike protein [13, 16-18, 40]. However, previous

221 studies with HIV-1 suggested that interferons also can shape the evolution of pandemic viruses

222 [41, 42]. In fact, SARS-CoV-2 infected individuals with either genetic defects in IFN signaling

223 [43] or IFN-reactive autoantibodies [44] had increased risk of developing severe COVID-19. As

224 interferons are critical in controlling early virus infection levels, IFN-resistant SARS-CoV-2

225 variants may produce higher viral loads that could in turn promote transmission and/or

226 exacerbate pathogenesis. Consistent with this hypothesis, some reports have linked B.1.1.7 with

227 increased viral loads [45, 46] and risk of death [47-49]. Notably, infection with B.1.617.2 may

228 yield even higher viral loads than that B.1.1.7 [50].

230 In addition to Spike, emerging variants exhibit mutations in nucleocapsid, membrane and

231 nonstructural proteins NSP3, NSP6 and NSP12 (S1 Table). In the case of some early pandemic

232 viruses that pre-dated the emergence of the variants of concern, these viral proteins were 
233 reported to antagonize IFN signaling in cells [51-53]. To specifically map the virus mutations

234 driving IFN-I resistance in emerging variants, it will be important to generate recombinant

235 viruses to isolate specific mutations, singly or in combination, and individually test candidate

236 single viral protein antagonists as well. This would help to confirm, for example, that the D3L

237 mutation in the B.1.1.7 nucleocapsid may facilitate innate immune evasion by increasing the

238 expression of an interferon antagonist, ORF9b [33]. The nucleocapsid D3L mutation was not

239 observed in the B.1.351, P.1 and B.1.617.2 lineages (S1 Table), which exhibited IFN-I and IFN-

240 III resistance in our experiments. B.1.617.2 (delta) has now replaced B.1.1.7 (alpha) as the

241 dominant strain in many countries [27, 29], but delta did not seem to be any more interferon-

242 resistant than alpha in both A549-ACE2 and Calu-3 cells. Notably, the delta isolate we studied

243 here had a deletion in ORF7a, which may counteract interferon signaling [52]; this deletion was

244 not a cell culture artifact as it was also observed in the clinical isolate. Analysis of delta isolates

245 with or without the ORF7a deletion would be needed to determine whether innate immune

246 evasion may be a factor for why the delta VOC has overtaken other lineages. Future studies

247 should facilitate understanding the molecular mechanisms of interferon resistance, its

248 consequences for COVID-19 pathogenesis, and the development of novel therapies that augment

249 innate immune defenses against SARS-CoV-2.

251 Overall, the current study suggested a role for the innate immune response in driving the

252 evolution of SARS-CoV-2 that could have practical implications for interferon-based therapies.

253 Our findings reinforce the importance of continued full-genome surveillance of SARS-CoV-2,

254 and assessments of emerging variants not only for resistance to vaccine-elicited neutralizing

255 antibodies, but also for evasion of the host interferon response. 
bioRxiv preprint doi: https://doi.org/10.1101/2021.03.20.436257; this version posted December 10, 2021. The copyright holder for this preprint (which was not certified by peer review) is the author/funder, who has granted bioRxiv a license to display the preprint in perpetuity. It is made available under aCC-BY-NC-ND 4.0 International license. 


\section{Materials and Methods}

Cell lines. A549 cells were obtained from the American Type Culture Collection (ATCC) and

260 cultured in complete media containing F-12 Ham's media (Corning), 10\% fetal bovine serum

261 (Atlanta Biologicals), 1\% penicillin/streptomycin/glutamine (Corning). Calu-3 cells were also

262 obtained from ATCC and cultured in DMEM supplemented with $10 \%$ fetal bovine serum and

$2631 \%$ penicillin/streptomycin/glutamine (Corning). Both cell lines were maintained at $37^{\circ} \mathrm{C} 5 \%$

$264 \mathrm{CO}_{2}$. A549 cells were transduced with codon-optimized human ACE2 (Genscript) cloned into

265 pBABE-puro [54] (Addgene). To generate the A549-ACE2 stable cell line, $10^{7}$ HEK293T

266 (ATCC) cells in T-175 flasks were transiently co-transfected with $60 \mu \mathrm{g}$ mixture of pBABE-

267 puro-ACE2, pUMVC, and pCMV-VSV-G at a 10:9:1 ratio using a calcium phosphate method

268 [55]. Forty-eight hours post transfection, the supernatant was collected, centrifuged at $1000 \times g$

269 for $5 \mathrm{~min}$ and passed through a $0.45 \mu \mathrm{m}$ syringe filter to remove cell debris. The filtered virus

270 was mixed with fresh media (30\% vol/vol) that included polybrene (Sigma) at a $6 \mu \mathrm{g} / \mathrm{ml}$ final

271 concentration. The virus mixture was added into 6-well plates with $5 \times 10^{5}$ A549 cells/well and

272 media was changed once more after $12 \mathrm{~h}$. Transduced cells were selected in $0.5 \mu \mathrm{g} / \mathrm{ml}$

273 puromycin for $72 \mathrm{~h}$, and ACE2 expression was confirmed by flow cytometry, western blot and

274 susceptibility to HIV-1 $\triangle$ Env/SARS-CoV-2 Spike pseudovirions.

276 Virus isolates. All experiments with live SARS-CoV-2 were performed in a Biosafety Level-3

277 (BSL3) facility with powered air-purifying respirators at the University of Colorado Anschutz

278 Medical Campus. The SARS-CoV-2 stocks were obtained from BEI Resources

279 (www.beiresources.org). S1 Table provides detailed information on the source of the material,

280 the catalogue and lot numbers and virus sequence information of both the clinical and cultured 
stocks. The viruses were propagated in human A549-ACE2 cells unless indicated and harvested by $72 \mathrm{~h}$ to minimize mutations that can occur during passage in cell culture, which were documented particularly in nonhuman primate (Vero) or non-alveolar type II (293T) cell lines

284 [56]. The virus stocks had comparable titers $>10^{6} \mathrm{TCID}_{50} / \mathrm{ml}$ (S1A Fig) except for the two vial ( $0.5 \mathrm{ml})$ were inoculated into 3 T-75 flasks containing $3 \times 10^{6}$ A549-ACE2 cells, except for B.1.1.7 which was inoculated into 1 T-75 flask. The supernatants were collected and spun at $2700 \times g$ for 5 min to remove cell debris, and frozen at $-80^{\circ} \mathrm{C}$. The A549-amplified stocks were titered according to the proposed assay format (S1B Fig, Fig 2A). Briefly, $2.5 \times 10^{4}$ A549-ACE2

290 cells were plated per well in a 48-well plate overnight. The next day, the cells were infected with $291300,30,3,0.3,0.03$ and $0.003 \mu 1$ (serial 10-fold dilution) of amplified virus stock in $300 \mu 1$ final

292 volume of media for $2 \mathrm{~h}$. The virus was washed twice with PBS, and $500 \mu \mathrm{l}$ of complete media

293 with the corresponding IFN concentrations were added. After 24 h, supernatants were collected, 294 and cell debris was removed by centrifugation at $3200 \times g$ for $5 \mathrm{~min}$.

296 Cell viability. To evaluate if the IFN doses affected cell viability, we utilized an MTT assay.

297 1.5 $\times 10^{4}$ A549-ACE2 cells were plated per well in a 96-well plate and treated with $2000 \mathrm{pM}$ 298 IFN $\lambda 1,2$ pM IFN $\lambda 1,200$ pM IFN $\beta, 2$ pM IFN $\beta$ or untreated. Eight replicates were used per 299 treatment group. As a positive control for cell death, the same number of cells were treated with

$30030 \%$ DMSO. 36 hours after treatment, cell proliferation was assessed using the Vybrant MTT 301 Cell Proliferation Assay Kit (Invitrogen). Media was completely removed from cells and 302 replaced with $100 \mu \mathrm{l}$ of fresh growth media. $10 \mu \mathrm{l}$ of $12 \mathrm{mM}$ MTT stock solution was added per 303 well and cells were incubated at $37^{\circ} \mathrm{C}$ for 4 h. $100 \mu \mathrm{l} \mathrm{SDS-HCl} \mathrm{solution} \mathrm{was} \mathrm{added} \mathrm{to} \mathrm{each} \mathrm{well}$ 
304 and mixed thoroughly. After an additional $3 \mathrm{~h}$ incubation at $37^{\circ} \mathrm{C}$, the absorbance was measured

305 at $570 \mathrm{~nm}$ and blank corrected to a media only control.

307 SARS-CoV-2 quantitative PCR. For rapid and robust assessments of viral replication, we

308 utilized a real-time quantitative PCR (qPCR) approach. This assay would require less handling of

309 infectious, potentially high-titer SARS-CoV-2 in the BSL3 compared to a VeroE6 plaque assay,

310 as the supernatants can be directly placed in lysis buffer containing guanidinium thiocyanate that

311 would inactivate the virus by at least $4-5 \log _{10}$ [57]. Importantly, residual IFNs in the culture

312 supernatant could further inhibit virus infection in the VeroE6 plaque assay, compromising the

313 infectious titer read-outs. To measure SARS-CoV-2 levels, total RNA was extracted from $100 \mu 1$

314 of culture supernatant using the E.Z.N.A Total RNA Kit I (Omega Bio-Tek) and eluted in $50 \mu 1$

315 of RNAse-free water. $5 \mu \mathrm{l}$ of this extract was used for qPCR. Official CDC SARS-CoV-2 N1

316 gene primers and TaqMan probe set were used [58] with the Luna Universal Probe One-Step

317 RT-qPCR Kit (New England Biolabs):

Reverse primer: $\quad$ TCTGGTTACTGCCAGTTGAATCTG

321 The sequence of the primers and probes were conserved against the 7 SARS-CoV-2 lineages that

322 were investigated. The real-time qPCR reaction was run on a Bio-Rad CFX96 real-time 323 thermocycler under the following conditions: $55^{\circ} \mathrm{C} 10$ mins for reverse transcription, then $95^{\circ} \mathrm{C}$

$3241 \mathrm{~min}$ followed by 40 cycles of $95^{\circ} \mathrm{C} 10 \mathrm{~s}$ and $60^{\circ} \mathrm{C} 30 \mathrm{~s}$. The absolute quantification of the $\mathrm{N} 1$

325 copy number was interpolated using a standard curve with $10^{7}-10^{1}$ serial 10 -fold dilution of a 326 control plasmid (nCoV-CDC-Control Plasmid, Eurofins). 
VeroE6 Plaque Assay. Virus stocks with a pre-determined virus copy number were evaluated

328 in a conventional VeroE6 plaque assay to determine if the virus titers obtained using both

329 methods correlate. $4 \times 10^{5}$ VeroE6 cells (ATCC) were plated in 6-well plates and allowed to

330 adhere overnight at $37^{\circ} \mathrm{C}$. Cells were washed once with PBS and infected with $1 \mathrm{ml}$ of viral

331 stocks serially diluted in 2× MEM complete media (10\% FBS, 20 mM HEPES, 2× Pen-Step, $2 \times$

332 NEAA and $2 \times$ Sodium Pyruvate) for $1 \mathrm{hr}$ at $37^{\circ} \mathrm{C}$. After infection, $1 \mathrm{ml}$ of sterile $2.5 \%$ cellulose

333 overlay solution (Sigma, Cat. No. 435244-250G) was added to each well and mixed thoroughly.

334 Cells were incubated at $37^{\circ} \mathrm{C}$ for an additional $48 \mathrm{hr}$ before the media/overlay was removed and

335 the cells fixed in $4 \%$ paraformaldehyde (PFA) for $10 \mathrm{~min}$ at room temperature. The PFA was

336 removed and the cells were stained with $1 \%$ crystal violet in ethanol for 1 minute and washed

337 three times with distilled water. Plaques were manually counted from each well.

339 Immunofluorescence Assay. Primary human airway epithelial cells fully differentiated in air-

340 liquid interface cultures [59] were infected with different SARS-CoV-2 variants with or without

341 IFN $\beta$. The apical surface was washed with culture medium daily for quantitative PCR. At $96 \mathrm{~h}$

342 post-infection, the cultures were fixed with 4\% PFA and wholemount labeled with anti-Spike

343 antibody (Clone ID007, Cat. No. 40150-R007, Sino Biological) followed by Alexa-Dye

344 conjugated secondary antibody. An LSM 900 confocal microscope (Zeiss) was used to generate

345 composite images of the entire culture surface. Spike+ cells were enumerated using the Cell

346 Counter plugin in the ImageJ Software (NIH).

348 Antiviral inhibition assay. We used a non-saturating dose of the amplified virus stock for the

349 IFN inhibition assays. These titers were expected to yield $\sim 10^{5}$ copies per $5 \mu$ input RNA extract 
(S1B Fig). Recombinant IFNs were obtained from PBL Assay Science. These recombinant IFNs were assayed to be $>95 \%$ pure by SDS-PAGE according to the manufacturer. In addition to the IFN-Is (12 IFN $\alpha$ subtypes, IFN $\beta$ and IFN $\omega$ ), we also evaluated 3 IFN $\lambda$ subtypes (IFN $\lambda 1$, IFN $\lambda 2$,

353 IFNג3). To normalize the IFNs, we used molar concentrations [23] instead of international units

354 (IU), as IU values were derived from inhibition of encelphalomyocarditis virus, which may not

355 be relevant to SARS-CoV-2. Importantly, molar concentrations were used to normalize the 356 relative signaling potencies of the IFN $\alpha$ subtypes and IFN $\beta[23,24]$. To find a suitable dose to

357 screen 17 IFNs in parallel, we performed a dose-titration experiment of the USA-WA1/2020

358 strain with IFN $\beta$ and IFN $\lambda 1$. A dose of $2 \mathrm{pM}$ allowed for maximum discrimination of the

359 antiviral potency IFN $\beta$ versus IFN 1 (S1C Fig). Thus, this dose should be within the dynamic 360 range of inhibition of the diverse IFNs investigated. Serial 10-fold dilutions of IFN $\beta$ and IFN $\lambda 1$

361 were also used in follow-up experiments. Thus, in 48 -well plates, we pre-incubated $2.5 \times 10^{4}$ 362 A549-ACE2 cells with the IFNs for $18 \mathrm{~h}$, then infected with the A549-amplified virus stock for 2 363 h. After two washes with PBS, $500 \mu \mathrm{l}$ complete media containing the corresponding IFNs were 364 added. The cultures were incubated for another $24 \mathrm{~h}$, after which, supernatants were harvested 365 for RNA extraction and qPCR analysis. A similar procedure was employed for Calu-3 cells, 366 except that IFN $\lambda 1$ was replenished at 2 dpi and supernatants harvested at day 3.

368 Statistical analyses. Data were analyzed using GraphPad Prism 8. Differences between the IFNs 369 were tested using a nonparametric two-way analysis of variance (ANOVA) followed by a 370 multiple comparison using the Friedman test. Pearson correlation coefficients $\left(\mathrm{R}^{2}\right)$ values were 371 computed for linear regression analyses. Paired analysis of two isolates against multiple IFNs 372 were performed using a nonparametric, two-tailed Wilcoxon matched-pairs rank test. Differences 
bioRxiv preprint doi: https://doi.org/10.1101/2021.03.20.436257; this version posted December 10,2021 . The copyright holder for this preprint (which was not certified by peer review) is the author/funder, who has granted bioRxiv a license to display the preprint in perpetuity. It is made available under aCC-BY-NC-ND 4.0 International license.

373 with $p<0.05$ were considered significant. Nonlinear regression curves were used to fit using

374 either a one-site total or two-phase exponential decay equation on log-transformed data. 


\section{Acknowledgments}

378 We thank Cara Wilson, Ulf Dittmer and Kathrin Gibbert for scientific advice; Mercedes Rincon

379 and Elan Eisenmesser for assistance with construction and characterization of the A549-ACE2

380 cells; Zach Wilson, Jill Garvey, Stephanie Torres-Nemeti, Brett Haltiwanger and Marcia

381 Finucane for Biosafety Level-3 infrastructure support; and Roman Wölfel, Rosina Ehmann,

382 Adolfo García-Sastre, Alex Sigal, Tulio de Oliveira, Bassam Hallis, Matsuyo Takayama-Ito,

383 Richard Webby, Anami Patel, Cathleen Seager, BEI Resources (NIAID) and the CDC for the

384 SARS-CoV-2 isolates.

386 Funding

387 This work was supported by the Division of Infectious Diseases, Department of Medicine,

388 University of Colorado (MLS and EMP), the National Institutes of Health R01 AI134220

389 (MLS), and the Intramural Research Program at the National Institute of Allergy and Infectious

390 Diseases, National Institutes of Health $(\mathrm{KJH})$. The funders had no role in study design, data

391 collection and analysis, decision to publish, or preparation of the manuscript. 


\section{$393 \quad$ Figures}

394 Figure 1. Selection of SARS-CoV-2 strains for IFN sensitivity studies. (A) Global

395 distribution of SARS-CoV-2 clades. GISAID.org plotted the proportion of deposited sequences

396 in designated clades against collection dates. The six isolates chosen are noted by colored dots.

397 (B) SARS-CoV-2 strains selected for this study included representatives of lineages A, B, B.1,

398 B.1.351 and B.1.1.7 (S1 Table). Lineage P.1 (which branched off from lineage B.1.1.28) and

399 B.1.617.2 were added after the initial manuscript submission; and was evaluated for IFN $\beta$ and

400 IFN $\lambda 1$ sensitivity. Lineage B isolates encode the D614G mutation associated with increased

401 transmissibility. Note that the B.1.1.7 strain was later updated to belong to the GISAID clade,

402 'GRY'. *Amino acid mutations were relative to the reference hCOV-19/Wuhan/WIV04/2019

403 sequence.

404

405 Figure 2. Sensitivity of SARS-CoV-2 strains to IFN-I and IFN-III interferons. (A) Antiviral

406 assay using recombinant IFNs (2 pM) in A549-ACE2 cells. The red line corresponds to the

407 qPCR detection limit (90 copies/reaction, or $1.8 \times 10^{4}$ copies/ml). (B) Viral copy numbers in

408 D614G+ isolates, showing a similar rank-order of IFNs from least to most potent. (C) The

409 average fold-inhibition relative to mock for lineage B, B.1, B.1.351 and B.1.1.7 isolates are

410 shown. The most potent IFNs are shown top to bottom. For all panels, bars and error bars

411 correspond to means and standard deviations.

413 Figure 3. Correlation between SARS-CoV-2 inhibition and biological properties of IFNa

414 subtypes. Log-transformed IFN-inhibition values relative to mock for the 5 different SARS-

415 CoV-2 strains were compared to previously published values on (A) $50 \%$ effective 
concentrations in the iLite assay, a reporter cell line encoding the IFN sensitive response element

417 of ISG15 linked to firefly luciferase [23]; (B) IFNAR2 subunit binding affinity, as measured by

418 surface plasmon resonance by the Schreiber group [24]; and (C) HIV-1 inhibition values, based

419 on \% inhibition of HIV-1 p24+ gut lymphocytes relative to mock as measured by flow cytometry

420 [3]. Each dot corresponds to an IFN $\alpha$ subtype. Linear regression was performed using GraphPad

421 Prism 8. Significant correlations $(p<0.05)$ were highlighted with a red best-fit line; those that

422 were trending $(p<0.1)$ had a gray, dotted best-fit line.

424 Figure 4. Increased IFN-I resistance of emerging SARS-CoV-2 variants. (A) Heatmap of

425 fold-inhibition of representative strains from the lineages noted. Colors were graded on a log426 scale from highest inhibition (yellow) to no inhibition (black). Comparison of IFN-I sensitivities

427 between (B) lineage A and B isolates; (C) lineage B versus B.1, B.1.351 and B.1.1.7 and (D)

428 lineage A versus B.1, B.1.351 and B.1.1.7. The mean fold-inhibition values relative to mock

429 were compared in a pairwise fashion for the 14 IFN-Is. In (C) and (D), the average fold-

430 inhibition values were noted. Differences were evaluated using a nonparametric, two-tailed

431 Wilcoxon matched-pairs signed rank test. NS, not significant; ****, $p<0.0001$.

433 Figure 5. Dose-titration of ancestral lineage B versus four variants of concern against IFN $\beta$

434 and IFN久1. Data from four separate experiments (panels A-D) are shown. (A) Dose-titration of 435 IFN $\beta$ and IFN $\lambda 1$ against lineage B (Germany/BavPat1/2020) versus B.1.1.7 (alpha) isolates. In 436 addition to USA/CA_CDC_5574/2020, we also evaluated a second B.1.1.7 isolate from the 437 United Kingdom (UK), England/204820464/2020. *The value at 200 pM IFN 1 for the lineage 438 B isolate was 0.54 , precluding efforts for finding a best-fit curve for IC50 determination; this 
439 datapoint was therefore not included in the curve fitting. (B) IC50 comparison between a lineage

440 B (Germany/BavPat1/2020) and a B.1.351 (beta) isolate (South Africa/KRISP-EC-

441 K005321/2020). (C) IC50 comparison between a lineage B isolate (Germany/BavPat1/2020) and

442 a P.1 (gamma) isolate (Japan/TY7-503/2021). (D) IC50 comparison between a lineage B isolate

443 (Germany/BavPat1/2020) and a B.1.617.2 (delta) isolate (USA/PHC658/2021). For all panels,

444 A549-ACE2 cells were pre-treated with serial 10-fold dilutions of IFNs for $18 \mathrm{~h}$ in triplicate and

445 then infected with SARS-CoV-2. Supernatants were collected after 24 h, SARS-CoV-2 N1 copy

446 numbers were determined by qPCR in triplicate, and then the mean copy numbers were

447 normalized against mock as $100 \%$. Error bars correspond to standard deviations. Non-linear best-

448 fit regression curves of mean normalized infection levels were used to interpolate $50 \%$ inhibitory

449 concentrations (green dotted lines). 


\section{References}

1. Pestka S, Krause CD, Walter MR. Interferons, interferon-like cytokines, and their receptors. Immunol Rev. 2004;202:8-32. Epub 2004/11/18.

2. Gibbert K, Schlaak JF, Yang D, Dittmer U. IFN-alpha subtypes: distinct biological activities in anti-viral therapy. British journal of pharmacology. 2013;168(5):1048-58.

3. Harper MS, Guo K, Gibbert K, Lee EJ, Dillon SM, Barrett BS, et al. Interferon-alpha Subtypes in an Ex Vivo Model of Acute HIV-1 Infection: Expression, Potency and Effector Mechanisms. PLoS pathogens. 2015;11(11):e1005254.

4. Schlaepfer E, Fahrny A, Gruenbach M, Kuster SP, Simon V, Schreiber G, et al. DoseDependent Differences in HIV Inhibition by Different Interferon Alpha Subtypes While Having Overall Similar Biologic Effects. mSphere. 2019;4(1). Epub 2019/02/15.

5. Lavender KJ, Gibbert K, Peterson KE, Van Dis E, Francois S, Woods T, et al. Interferon Alpha Subtype-Specific Suppression of HIV-1 Infection In Vivo. Journal of virology. 2016;90(13):6001-13.

6. Matos ADR, Wunderlich K, Schloer S, Schughart K, Geffers R, Seders M, et al. Antiviral potential of human IFN-alpha subtypes against influenza A H3N2 infection in human lung explants reveals subtype-specific activities. Emerg Microbes Infect. 2019;8(1):1763-76.

7. Vanderheiden A, Ralfs P, Chirkova T, Upadhyay AA, Zimmerman MG, Bedoya S, et al. Type I and Type III Interferons Restrict SARS-CoV-2 Infection of Human Airway Epithelial Cultures. Journal of virology. 2020;94(19). Epub 2020/07/24.

8. Felgenhauer U, Schoen A, Gad HH, Hartmann R, Schaubmar AR, Failing K, et al. Inhibition of SARS-CoV-2 by type I and type III interferons. The Journal of biological chemistry. 2020;295(41):13958-64. Epub 2020/06/27.

9. Nchioua R, Kmiec D, Muller JA, Conzelmann C, Gross R, Swanson CM, et al. SARS-CoV-2 Is Restricted by Zinc Finger Antiviral Protein despite Preadaptation to the Low-CpG Environment in Humans. mBio. 2020;11(5). Epub 2020/10/18.

10. Wang N, Zhan Y, Zhu L, Hou Z, Liu F, Song P, et al. Retrospective Multicenter Cohort Study Shows Early Interferon Therapy Is Associated with Favorable Clinical Responses in COVID-19 Patients. Cell host \& microbe. 2020;28(3):455-64 e2. Epub 2020/07/25.

11. Monk PD, Marsden RJ, Tear VJ, Brookes J, Batten TN, Mankowski M, et al. Safety and efficacy of inhaled nebulised interferon beta-1a (SNG001) for treatment of SARS-CoV-2 infection: a randomised, double-blind, placebo-controlled, phase 2 trial. Lancet Respir Med. 2020. Epub 2020/11/16.

12. Shalhoub S. Interferon beta-1b for COVID-19. Lancet. 2020;395(10238):1670-1. Epub 2020/05/14.

13. Rambaut A, Holmes EC, O'Toole A, Hill V, McCrone JT, Ruis C, et al. A dynamic nomenclature proposal for SARS-CoV-2 lineages to assist genomic epidemiology. Nat Microbiol. 2020;5(11):1403-7. Epub 2020/07/17.

14. Zhou P, Yang XL, Wang XG, Hu B, Zhang L, Zhang W, et al. A pneumonia outbreak associated with a new coronavirus of probable bat origin. Nature. 2020;579(7798):270-3. 
15. Worobey M, Pekar J, Larsen BB, Nelson MI, Hill V, Joy JB, et al. The emergence of SARSCoV-2 in Europe and North America. Science (New York, NY. 2020;370(6516):564-70. Epub 2020/09/12.

16. Korber B, Fischer WM, Gnanakaran S, Yoon H, Theiler J, Abfalterer W, et al. Tracking Changes in SARS-CoV-2 Spike: Evidence that D614G Increases Infectivity of the COVID19 Virus. Cell. 2020;182(4):812-27 e19. Epub 2020/07/23.

17. Plante JA, Liu Y, Liu J, Xia H, Johnson BA, Lokugamage KG, et al. Spike mutation D614G alters SARS-CoV-2 fitness. Nature. 2020. Epub 2020/10/28.

18. Hou YJ, Chiba S, Halfmann P, Ehre C, Kuroda M, Dinnon KH, 3rd, et al. SARS-CoV-2 D614G variant exhibits efficient replication ex vivo and transmission in vivo. Science (New York, NY. 2020;370(6523):1464-8. Epub 2020/11/14.

19. Gonzalez-Reiche AS, Hernandez MM, Sullivan MJ, Ciferri B, Alshammary H, Obla A, et al. Introductions and early spread of SARS-CoV-2 in the New York City area. Science (New York, NY. 2020;369(6501):297-301. Epub 2020/05/31.

20. Wibmer CK, Ayres F, Hermanus T, Madzivhandila M, Kgagudi P, Oosthuysen B, et al. SARS-CoV-2 501Y.V2 escapes neutralization by South African COVID-19 donor plasma. Nature medicine. 2021. Epub 2021/03/04.

21. Wang P, Nair MS, Liu L, Iketani S, Luo Y, Guo Y, et al. Antibody Resistance of SARSCoV-2 Variants B.1.351 and B.1.1.7. Nature. 2021. Epub 2021/03/09.

22. Galloway SE, Paul P, MacCannell DR, Johansson MA, Brooks JT, MacNeil A, et al. Emergence of SARS-CoV-2 B.1.1.7 Lineage - United States, December 29, 2020-January 12, 2021. MMWR Morb Mortal Wkly Rep. 2021;70(3):95-9. Epub 2021/01/22.

23. Guo K, Shen G, Kibbie J, Gonzalez T, Dillon SM, Smith HA, et al. Qualitative Differences Between the IFNalpha subtypes and IFNbeta Influence Chronic Mucosal HIV-1 Pathogenesis. PLoS pathogens. 2020;16(10):e1008986. Epub 2020/10/17.

24. Lavoie TB, Kalie E, Crisafulli-Cabatu S, Abramovich R, DiGioia G, Moolchan K, et al. Binding and activity of all human alpha interferon subtypes. Cytokine. 2011;56(2):282-9.

25. Faria NR, Mellan TA, Whittaker C, Claro IM, Candido DDS, Mishra S, et al. Genomics and epidemiology of the P.1 SARS-CoV-2 lineage in Manaus, Brazil. Science (New York, NY. 2021;372(6544):815-21. Epub 2021/04/16.

26. Naveca FG, Nascimento V, de Souza VC, Corado AL, Nascimento F, Silva G, et al. COVID19 in Amazonas, Brazil, was driven by the persistence of endemic lineages and P.1 emergence. Nature medicine. 2021. Epub 2021/05/27.

27. Mlcochova P, Kemp S, Dhar MS, Papa G, Meng B, Mishra S, et al. SARS-CoV-2 B.1.617.2 Delta variant emergence and vaccine breakthrough. Research Square Platform LLC.

28. Singh J, Rahman SA, Ehtesham NZ, Hira S, Hasnain SE. SARS-CoV-2 variants of concern are emerging in India. Nature medicine. 2021;27(7):1131-3. Epub 2021/05/29.

29. Monitoring Variant Proportions [Internet]. 2021. Available from: https://covid.cdc.gov/covid-data-tracker/\#variant-proportions. 
30. Chia PY, Ong SWX, Chiew CJ, Ang LW, Chavatte JM, Mak TM, et al. Virological and serological kinetics of SARS-CoV-2 Delta variant vaccine-breakthrough infections: a multicenter cohort study. medRxiv. 2021.

31. Brown CM, Vostok J, Johnson H, Burns M, Gharpure R, Sami S, et al. Outbreak of SARSCoV-2 Infections, Including COVID-19 Vaccine Breakthrough Infections, Associated with Large Public Gatherings - Barnstable County, Massachusetts, July 2021. MMWR Morb Mortal Wkly Rep. 2021;70(31):1059-62. Epub 2021/08/06.

32. Guo K, Barrett BS, Mickens KL, Hasenkrug KJ, Santiago ML. Interferon Resistance of Emerging SARS-CoV-2 Variants. bioRxiv. 2021. Epub 2021/03/25.

33. Thorne LG, Bouhaddou M, Reuschl AK, Zuliani-Alvarez L, Polacco B, Pelin A, et al. Evolution of enhanced innate immune evasion by the SARS-CoV-2 B.1.1.7 UK variant. bioRxiv. 2021. Epub 2021/06/16.

34. Holmes EC, Goldstein SA, Rasmussen AL, Robertson DL, Crits-Christoph A, Wertheim JO, et al. The origins of SARS-CoV-2: A critical review. Cell. 2021. Epub 2021/09/05.

35. Davidson S, McCabe TM, Crotta S, Gad HH, Hessel EM, Beinke S, et al. IFNlambda is a potent anti-influenza therapeutic without the inflammatory side effects of IFNalpha treatment. EMBO molecular medicine. 2016;8(9):1099-112.

36. Ng CT, Sullivan BM, Teijaro JR, Lee AM, Welch M, Rice S, et al. Blockade of interferon Beta, but not interferon alpha, signaling controls persistent viral infection. Cell host \& microbe. 2015;17(5):653-61.

37. Channappanavar R, Fehr AR, Zheng J, Wohlford-Lenane C, Abrahante JE, Mack M, et al. IFN-I response timing relative to virus replication determines MERS coronavirus infection outcomes. J Clin Invest. 2019;130:3625-39.

38. Channappanavar R, Fehr AR, Vijay R, Mack M, Zhao J, Meyerholz DK, et al. Dysregulated Type I Interferon and Inflammatory Monocyte-Macrophage Responses Cause Lethal Pneumonia in SARS-CoV-Infected Mice. Cell host \& microbe. 2016;19(2):181-93.

39. Schuhenn J, Meister TL, Todt D, Bracht T, Schork K, Billaud J-N, et al. Differential interferon-alpha subtype immune signatures suppress SARS-CoV-2 infection. BioRxiv. 2021.

40. Weisblum Y, Schmidt F, Zhang F, DaSilva J, Poston D, Lorenzi JC, et al. Escape from neutralizing antibodies by SARS-CoV-2 spike protein variants. Elife. 2020;9. Epub 2020/10/29.

41. Iyer SS, Bibollet-Ruche F, Sherrill-Mix S, Learn GH, Plenderleith L, Smith AG, et al. Resistance to type 1 interferons is a major determinant of HIV-1 transmission fitness. Proceedings of the National Academy of Sciences of the United States of America. 2017;114(4):E590-E9. Epub 2017/01/11.

42. Parrish NF, Gao F, Li H, Giorgi EE, Barbian HJ, Parrish EH, et al. Phenotypic properties of transmitted founder HIV-1. Proceedings of the National Academy of Sciences of the United States of America. 2013;110(17):6626-33. 
43. Zhang Q, Bastard P, Liu Z, Le Pen J, Moncada-Velez M, Chen J, et al. Inborn errors of type I IFN immunity in patients with life-threatening COVID-19. Science (New York, NY. 2020;370(6515). Epub 2020/09/26.

44. Bastard P, Rosen LB, Zhang Q, Michailidis E, Hoffmann HH, Zhang Y, et al. Autoantibodies against type I IFNs in patients with life-threatening COVID-19. Science (New York, NY. 2020;370(6515). Epub 2020/09/26.

45. Kidd M, Richter A, Best A, Cumley N, Mirza J, Percival B, et al. S-variant SARS-CoV-2 lineage B1.1.7 is associated with significantly higher viral loads in samples tested by ThermoFisher TaqPath RT-qPCR. The Journal of infectious diseases. 2021. Epub 2021/02/14.

46. Frampton D, Rampling T, Cross A, Bailey H, Heaney J, Byott M, et al. Genomic characteristics and clinical effect of the emergent SARS-CoV-2 B.1.1.7 lineage in London, UK: a whole-genome sequencing and hospital-based cohort study. Lancet Infectious Diseases. 2021.

47. Grint DJ, Wing K, Williamson E, McDonald HI, Bhaskaran K, Evans D, et al. Case fatality risk of the SARS-CoV-2 variant of concern B.1.1.7 in England, 16 November to 5 February. Euro Surveill. 2021;26(11). Epub 2021/03/20.

48. Davies NG, Jarvis CI, Group CC-W, Edmunds WJ, Jewell NP, Diaz-Ordaz K, et al. Increased mortality in community-tested cases of SARS-CoV-2 lineage B.1.1.7. Nature. 2021. Epub 2021/03/17.

49. Challen R, Brooks-Pollock E, Read JM, Dyson L, Tsaneva-Atanasova K, Danon L. Risk of mortality in patients infected with SARS-CoV-2 variant of concern 202012/1: matched cohort study. BMJ. 2021;372:n579. Epub 2021/03/11.

50. Ong SWX, Chiew CJ, Ang LW, Mak TM, Cui L, Toh M, et al. Clinical and virological features of SARS-CoV-2 variants of concern: a retrospective cohort study comparing B.1.1.7 (Alpha), B.1.315 (Beta), and B.1.617.2 (Delta). Clin Infect Dis. 2021. Epub 2021/08/24.

51. Lei X, Dong X, Ma R, Wang W, Xiao X, Tian Z, et al. Activation and evasion of type I interferon responses by SARS-CoV-2. Nat Commun. 2020;11(1):3810. Epub 2020/08/01.

52. Xia H, Cao Z, Xie X, Zhang X, Chen JY, Wang H, et al. Evasion of Type I Interferon by SARS-CoV-2. Cell reports. 2020;33(1):108234. Epub 2020/09/28.

53. Mu J, Fang Y, Yang Q, Shu T, Wang A, Huang M, et al. SARS-CoV-2 N protein antagonizes type I interferon signaling by suppressing phosphorylation and nuclear translocation of STAT1 and STAT2. Cell Discov. 2020;6:65. Epub 2020/09/22.

54. Morgenstern JP, Land H. Advanced mammalian gene transfer: high titre retroviral vectors with multiple drug selection markers and a complementary helper-free packaging cell line. Nucleic acids research. 1990;18(12):3587-96. Epub 1990/06/25.

55. Dillon SM, Guo K, Castleman MJ, Santiago ML, Wilson CC. Quantifying HIV-1-Mediated Gut CD4+ T Cell Death in the Lamina Propria Aggregate Culture (LPAC) Model BioProtocol. 2020;10(2). 
608

609

610

611

612

613

614

615

616

617

618

619

620
56. Sasaki M, Uemura K, Sato A, Toba S, Sanaki T, Maenaka K, et al. SARS-CoV-2 variants with mutations at the S1/S2 cleavage site are generated in vitro during propagation in TMPRSS2-deficient cells. PLoS pathogens. 2021;17(1):e1009233. Epub 2021/01/22.

57. Pastorino B, Touret F, Gilles M, Luciani L, de Lamballerie X, Charrel RN. Evaluation of Chemical Protocols for Inactivating SARS-CoV-2 Infectious Samples. Viruses. 2020;12(6). Epub 2020/06/12.

58. CDC. Research Use Only 2019-Novel Coronavirus (2019-nCoV) Real-time RT-PCR Primers and Probes. https://www.cdc.gov/coronavirus/2019-ncov/lab/rt-pcr-panel-primerprobes.html. 2020.

59. Robinot R, Hubert M, de Melo GD, Lazarini F, Bruel T, Smith N, et al. SARS-CoV-2 infection induces the dedifferentiation of multiciliated cells and impairs mucociliary clearance. Nat Commun. 2021;12(1):4354. Epub 2021/07/18. 


\section{A Global Clade Distribution}

(GISAID.org, as of 8/12/2021)

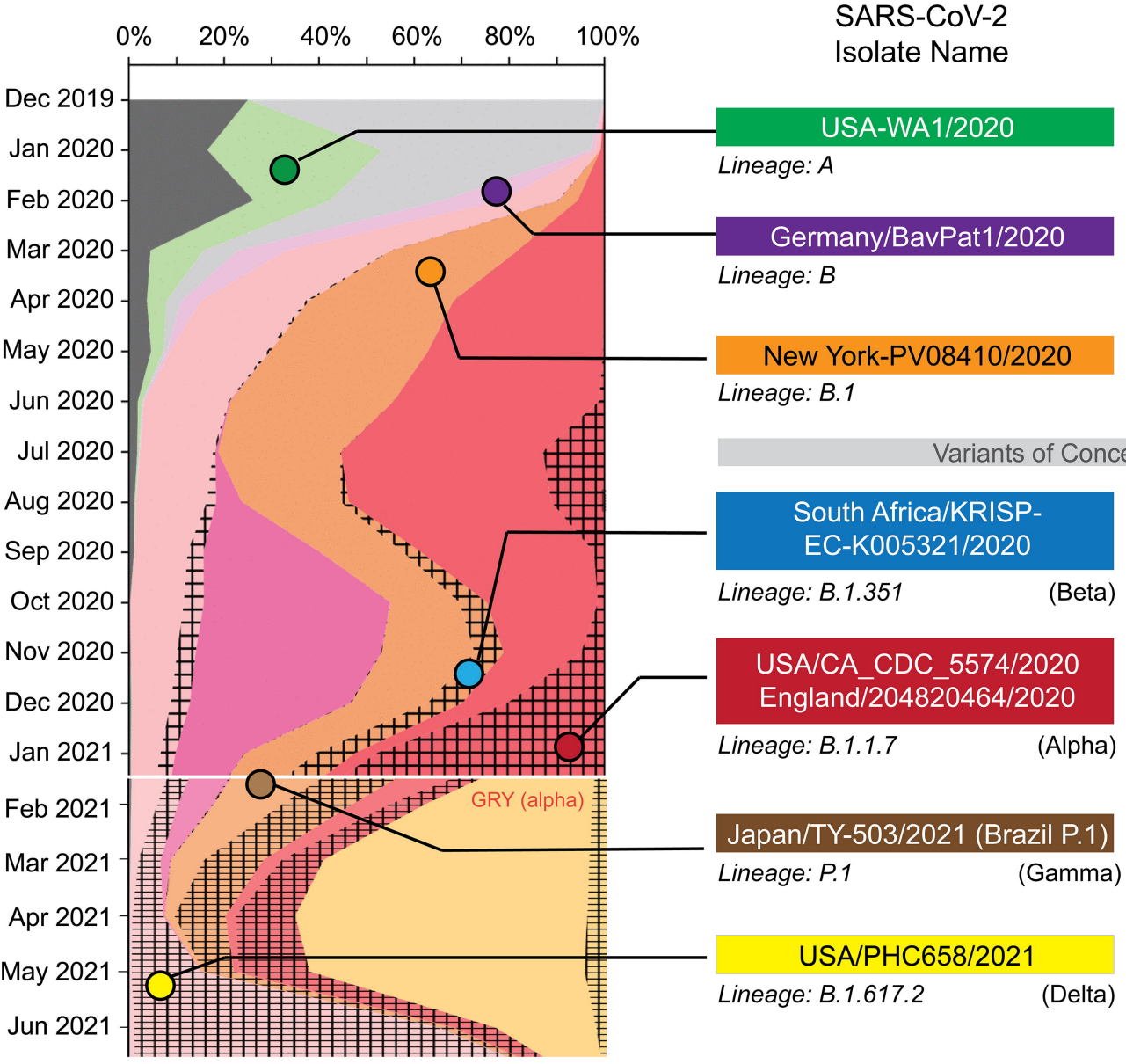

Notable Mutations in Spike (and other genes)*

\section{None \\ (NS8 L84S)}

\section{D614G}

(no mutations in other genes)

\section{D614G}

(NSP2 T85I, NSP12 P323L, NS3 Q57H)
D614G, N501Y, E484K

+ many others

D614G, N501Y

+ many others

D614G, N501Y, E484K

+ many others

D614G, L452R

+ many others

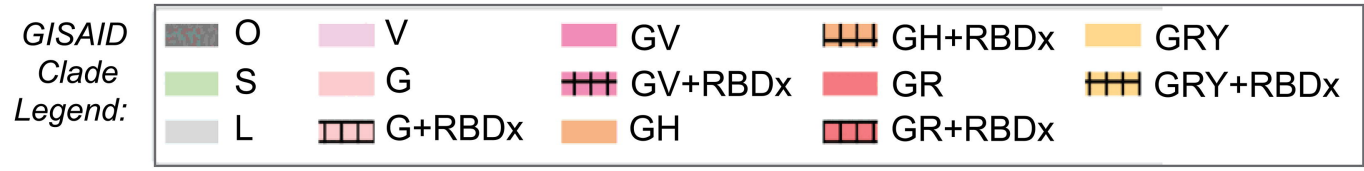


IFN $\alpha$ subtypes: relationship between IFNAR signaling and SARS-CoV-2 inhibition
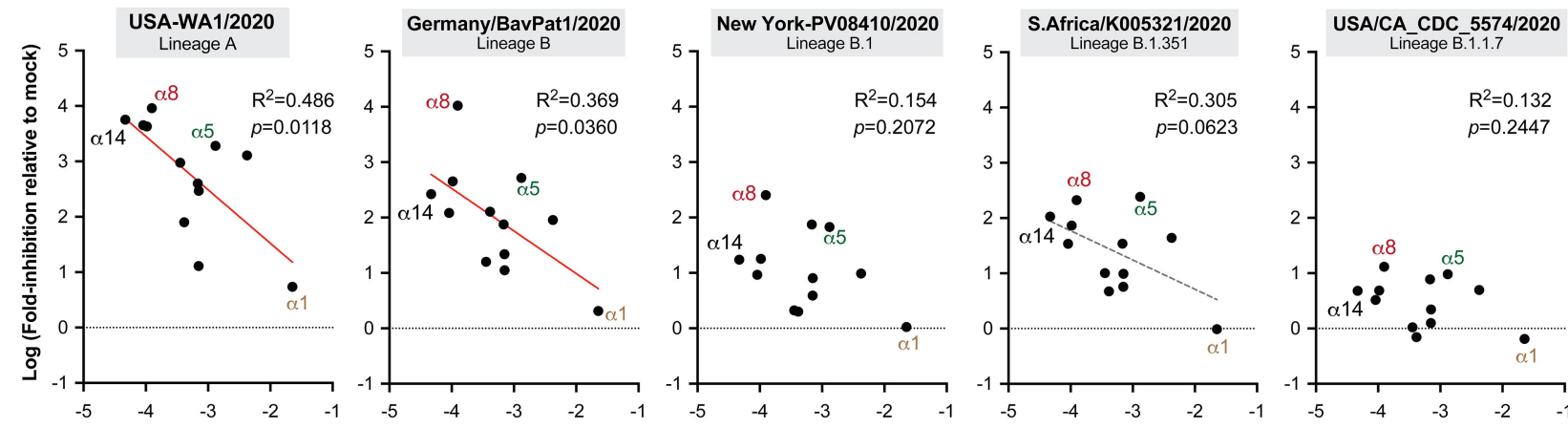

iLite: $\log (\mathrm{EC} 50)$

IFN $\alpha$ subtypes: relationship between IFNAR2 binding affinity and SARS-CoV-2 inhibition
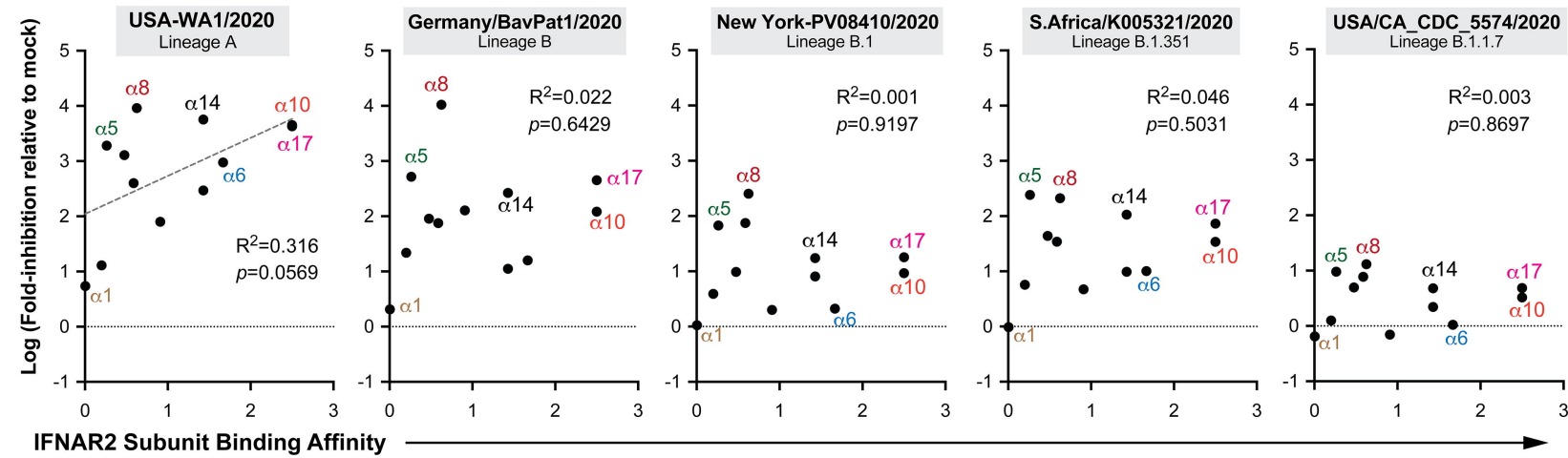

IFNAR2 Subunit Binding Affinity

C

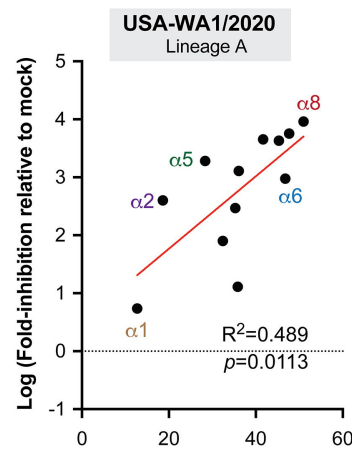

$\%$ HIV-1 inhibition
IFN $\alpha$ subtypes: relationship between inhibition of HIV-1 and SARS-CoV-2
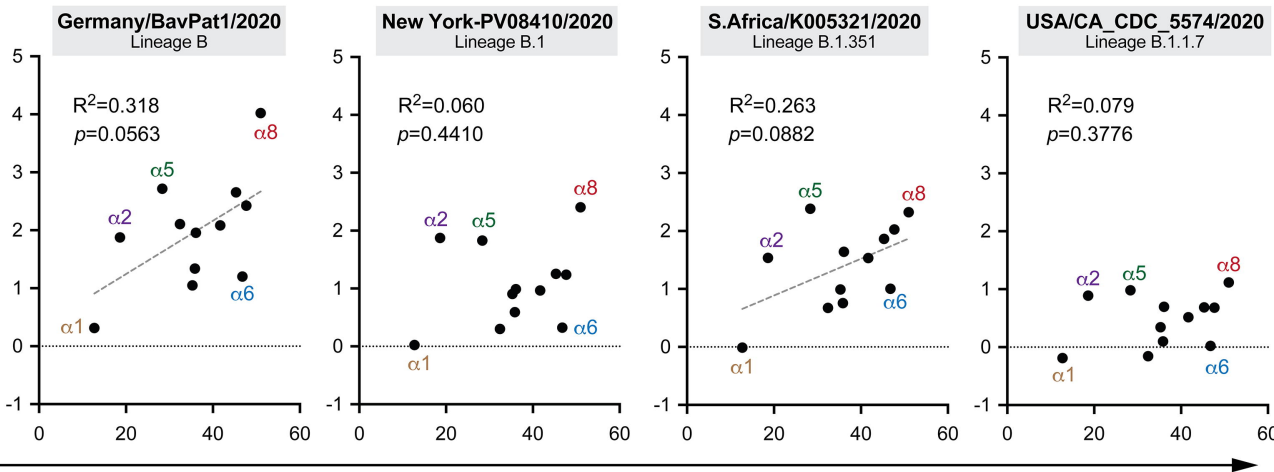

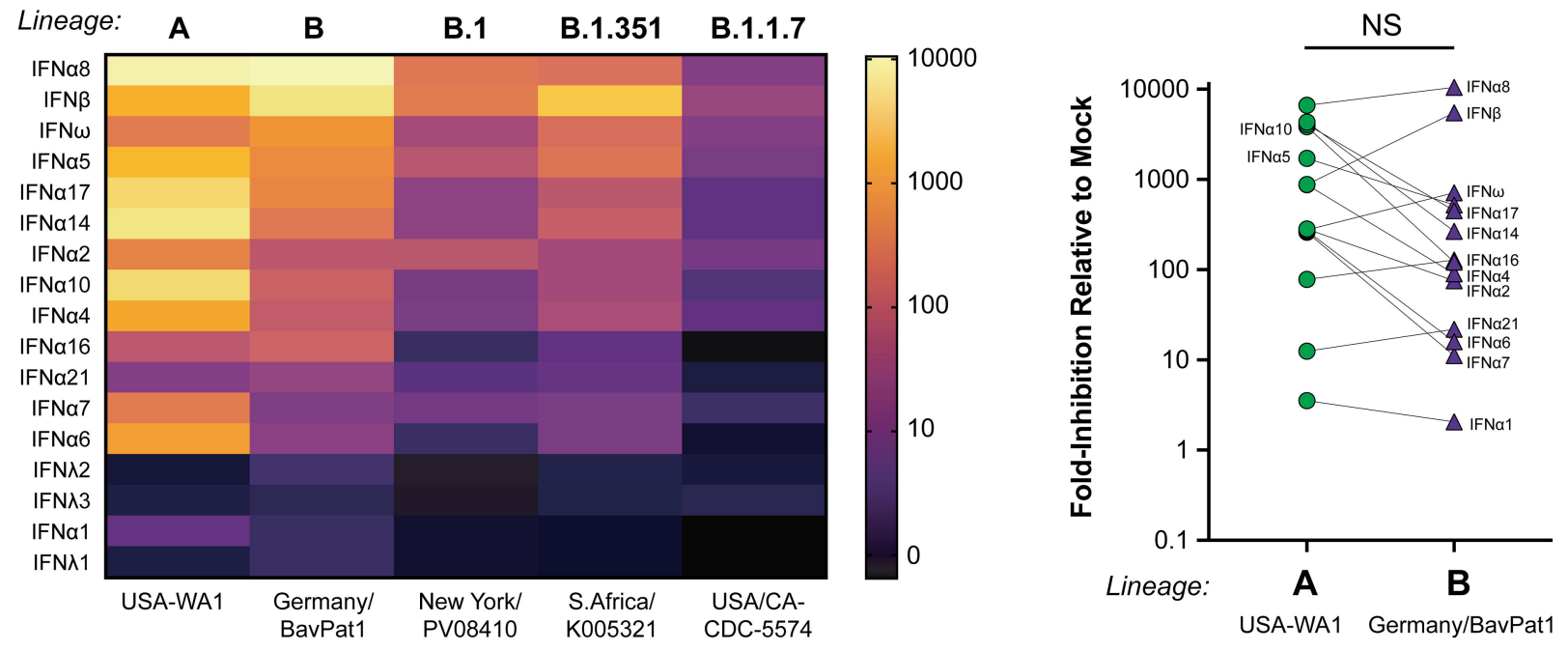

IFN-I resistance of SARS-CoV-2 variants (relative to lineage B)

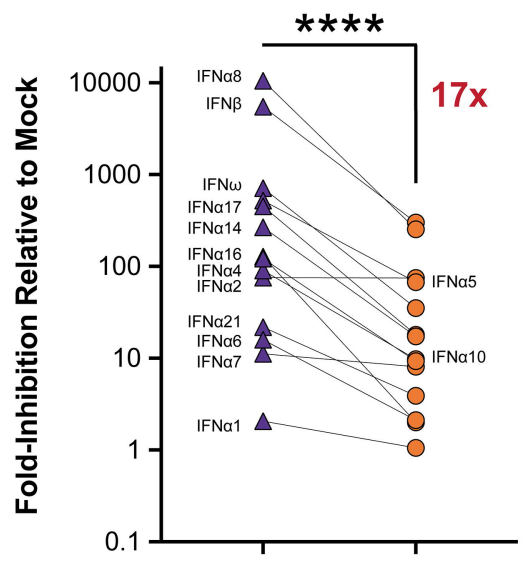

Lineage: B $\quad$ B.1

Germany/ New York/ BavPat1 PV08410

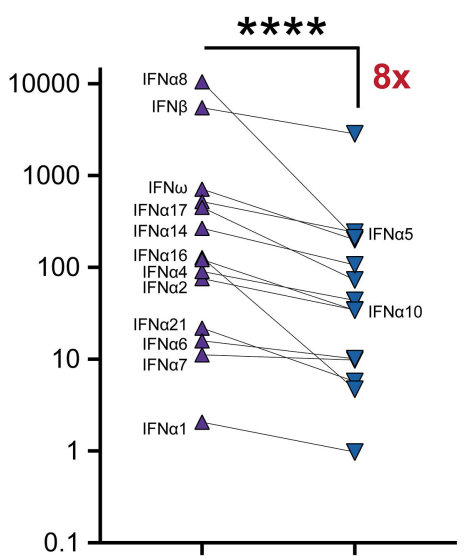

B B.1.351

Germanyl S.Africal BavPat1 K005321

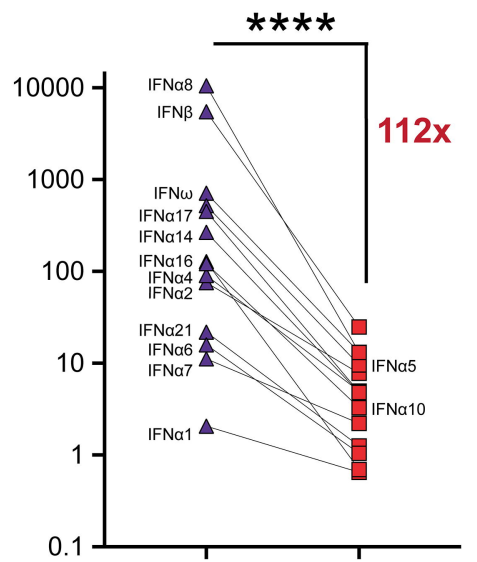

B

B.1.1.7

Germany/ USA/CABavPat1 CDC-5574

\section{IFN-I resistance of SARS-CoV-2 variants (relative to lineage A)}

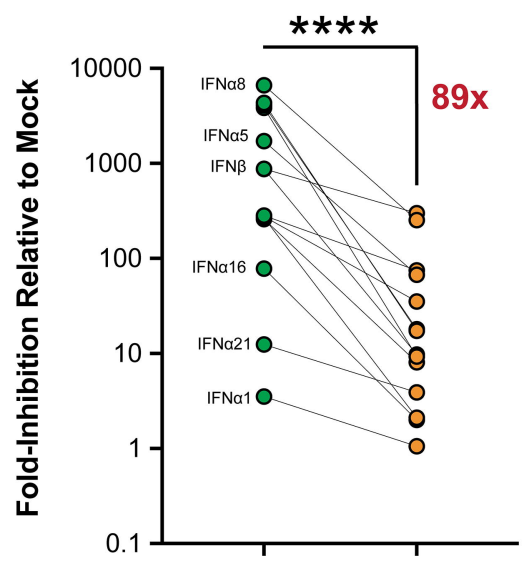

Lineage: A $\quad$ B.1

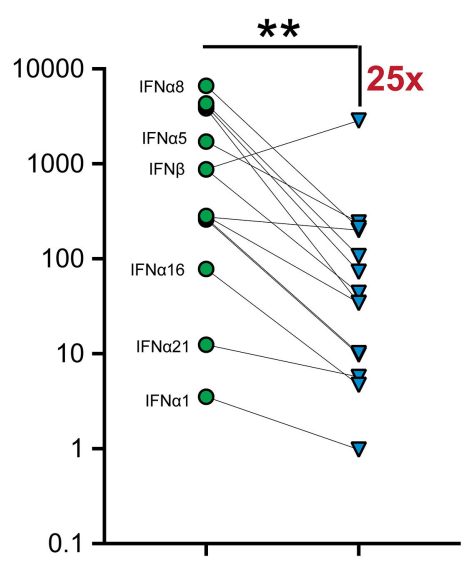

A

B.1.351 PV08410

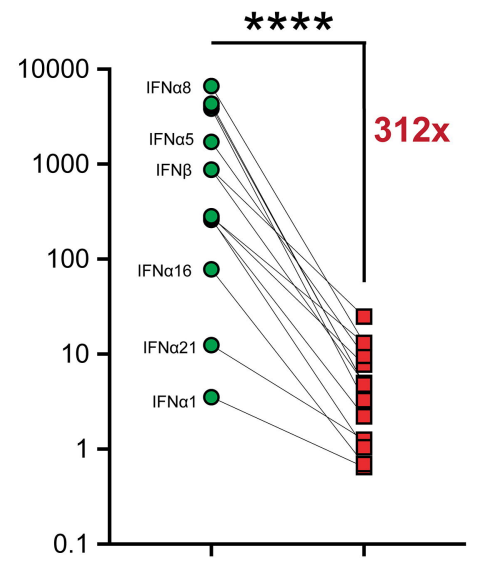

A

B.1.1.7 
Dose-titration of IFN $\beta$ and IFN $\lambda 1$
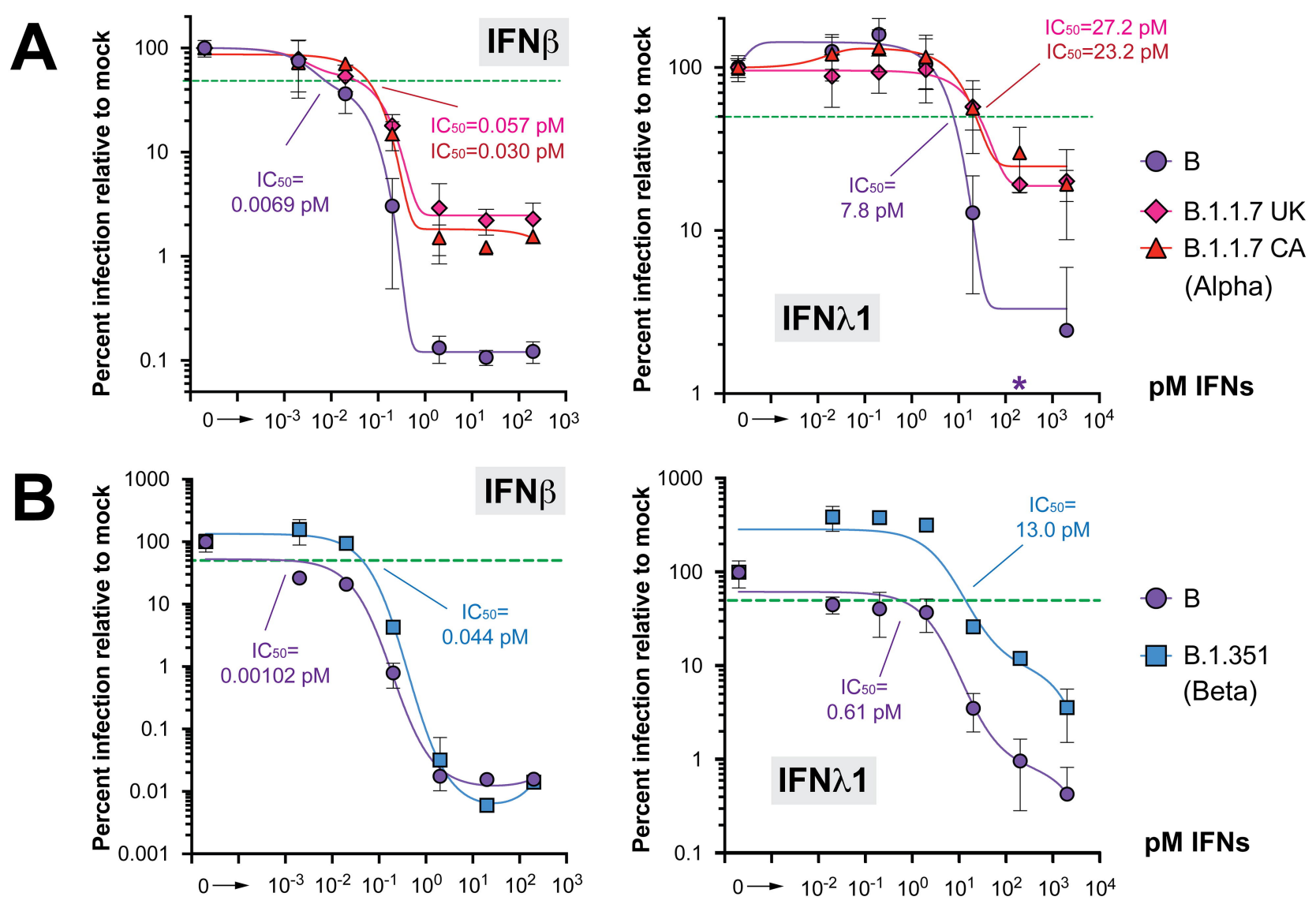

C
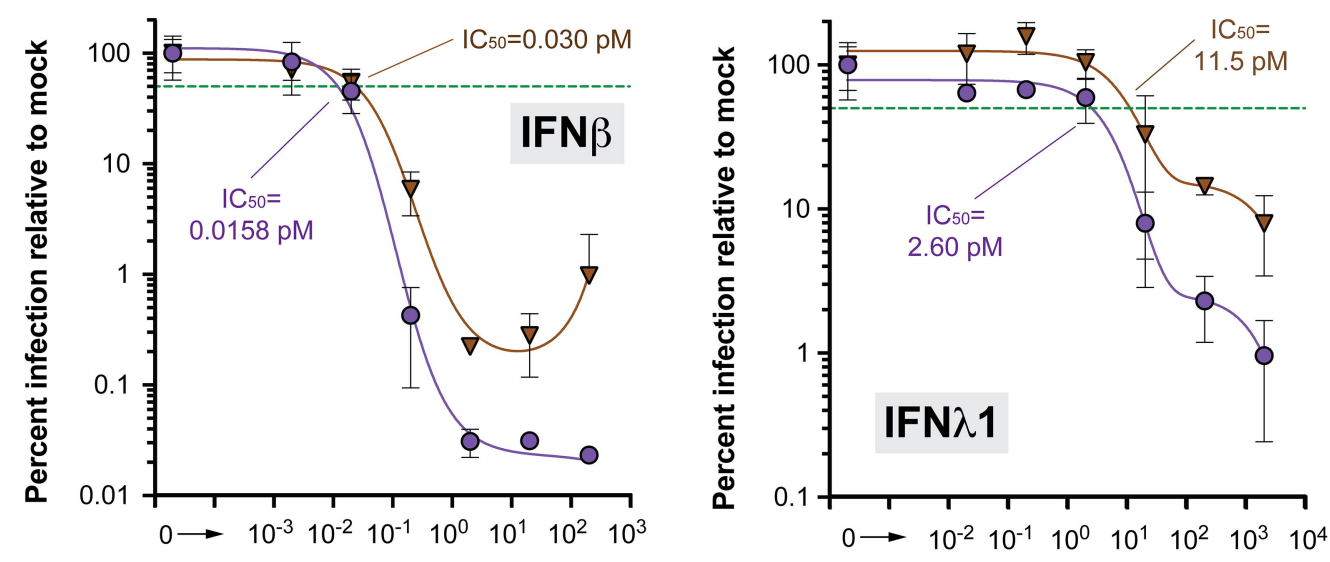

- B
$-\nabla$ P.1

(Gamma)

pM IFNs

D
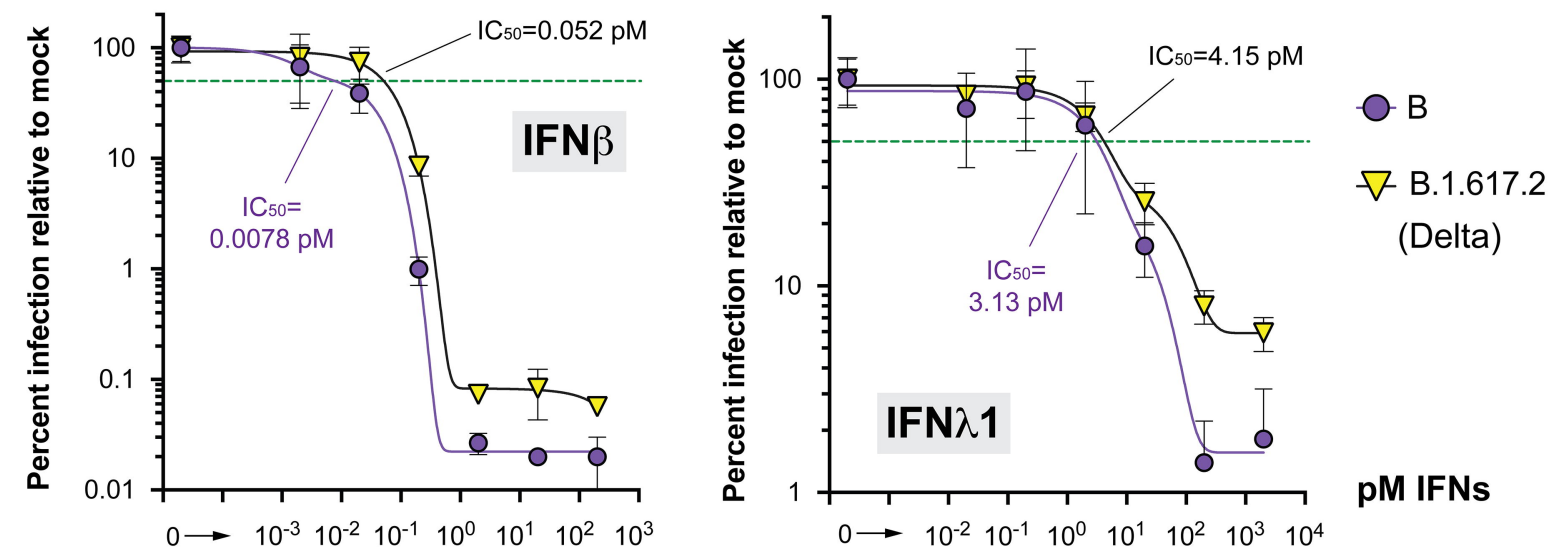